\title{
The Problem With Current Proposals to Address High Medicare Part B Drug Prices
}

Therapeutic Innovation \& Regulatory Science

2019, Vol. 53(6) 721-723 (C) DIA 2019

Article reuse guidelines: sagepub.com/journals-permissions DOI: I0.II77/2I684790I9889689 tirs.sagepub.com
Prices for some of the newest Medicare Part B drugs are hightoo high as many suggest. Medicare fee-spending for Part B Drugs has increased from $\$ 17.6$ billion in 2011 to $\$ 28$ billion in 2016. This translates to a $9.8 \%$ annual growth rate and per capita spending increase by $54 \%$. $^{1}$ From Democratic Presidential candidates, to both houses of Congress, to the Trump administration itself - the issue is front and center in Washington D.C. and all have ideas on how to address it. One theme that seems to resonate with Americans and therefore a component of several proposals is the comparison between how much Americans pay for these drugs as compared to other countries. In October 2018, Health and Human Services (HHS) Secretary Alex Azar at an event at the Brookings Institution noted that Medicare pays on average nearly twice what other countries pay for the same drugs in the Part B program and pledged that we will go from paying $180 \%$ to $126 \%$ of the average international price over the next 5 years. The proposal itself, the International Pricing Index (IPI) Model, was outlined by the Centers for Medicare \& Medicaid Services (CMS) in an Advance Notice of Proposed Rulemaking (ANPRM) ${ }^{1}$ and has generated much debate.

Unintended consequences of the IPI Model and proposals like it is the source of widespread criticism, including a recent Commentary in this issue of TIRS by Schulthess, Gassull, and Maisel. ${ }^{2}$ Criticisms stem from the potential impact of price caps tied to foreign government negotiations on R\&D and ultimate availability of innovative therapies for patients. Drugs of focus in the IPI model-Part B drugs that are sole source or biologics - are also the very same drugs that represent some of the most innovative, complex drugs in the pharmaceutical pipeline that address significant areas of unmet need. They also happen to be among the most risky endeavors from an investment perspective. Penalizing successful R\&D in these areas will likely be consequential for innovation in the ultimate availability of innovative treatments that patients need.

Pharmaceutical companies aren't entirely without blame as to why we are here with regard to public sentiment on drug prices. The price gauging "bad actors" that increase prices of sole-source generic products simply because they can and opaque pricing tactics that have nothing to do with the benefits a product brings to patients haven't helped. As a result, punitive price-setting proposals that ultimately set prices for innovative treatments in ways that ignore their benefits will be here unless the industry and stakeholder community broadly embrace more transparent approaches that bring better evidence, including real-world evidence, value, and patient priorities into the equation.

\section{Summary of the IPI Model}

Key components of the IPI model:

- Phasing down the amount Medicare Part B pays for single source drugs and biologicals to more closely align with international prices. Creates a Target Price based on an "International Price Index" that accounts for the price paid for the same drugs in select foreign countries;

- Moving physicians out from the "buy and bill" practice and allowing vendors instead to negotiate prices for Part B drugs in a competitive model. Providers would no longer acquire the drugs or seek reimbursement from Medicare under this model.

- Changing the providers' add-on payment to reflect the historical $6 \%$ payment (vs the $4.3 \%$ post-sequestration), by changing it to a flat amount to avoid incentives for prescribing higher-cost drugs that currently exist with $\mathrm{ASP}+\mathrm{X} \%$ payment methodology.

- CMS is currently considering this proposed rule with a plan for it to be tested in $50 \%$ of the Medicare market starting in 2020 and lasting for 5 years.

Schulthess et al conducted an empirical analysis and highlighted several flaws in the proposal that could result in unintended negative impacts on R\&D budgets, external investment in firms, and ultimately availability of innovative therapies for patients. Their focus was on the price determination component rather than the other aspects of the proposal such as incorporating vendors in lieu of "buy and bill" and changing the physician add-on to a fixed payment.

\section{Impact of the IPI Model on R\&D, Prices, and Innovation}

The first flaw highlighted includes more than the suggested negative impact on company R\&D budgets. According to the analysis by Schulthess et al, decreased revenues as a result of the IPI model when rolled out beyond the 5-year test would double the expected impact on R\&D budgets. In fact, for companies that have multiple implicated products, the impact would near $10 \%$ of the company's R\&D budget. One big unknown about the ultimate impact on a company's R\&D budget is the impact on 
revenues outside of Medicare Part B, such as in the Medicaid programs as well as the commercial sector. While some have suggested that companies will just make up the revenue reduction caused by the IPI model by simply increasing prices offered to commercial insurance plans or prices offered in Europe, both seem to be very unlikely. Schulthess et al are clear that the likely impact in the US commercial market is further price erosion through negotiation when the much lower Part B price is publicly known. They suggest a reduction of 5 times Secretary Azar's estimated 1\% impact reduction in R\&D. Others further argue that by default of the Medicare Drug Rebate Program, if IPI sales in the Medicare Part B program weren't exempted, then the "best price" requirement for state Medicaid programs would automatically trigger a larger rebate that manufacturers would have to offer state Medicaid programs. ${ }^{3}$ Further compounding the net impact on innovation, Schulthess et al highlighted results from an empirical analysis that suggests that decreased R\&D resulting in decreased likelihood of FDA approval success translates to less investments from across the ecosystem including acquisition partnerships, private equity investments, public offerings, and venture capital financing, which are significant for small start-up firms.

Other challenges raised include more longer-term impacts such as companies choosing to not invest in drugs that would fall into Medicare Part B or choosing not to sell drugs to the foreign countries that are the reference countries for the IPIboth of which would directly result in less availability of needed therapies for patients.

Beyond the Schulthess critique, more promising elements of the IPI model include introduction of market competition through adding vendors to negotiate prices with manufacturers. However, it is unclear as to whether the vendors would choose to enter the market if the price they are ultimately reimbursed through the IPI Model is set lower than what they will be able to negotiate from the companies. This is because the IPI Model would only determine the prices that CMS pays to vendors, not the acquisition cost that vendors would pay manufacturers. Also, moving away from physician practice "buy and bill," and changing the payment to physicians for the administration to a fixed fee holds promise to remove incentives to use more expansive therapies than would otherwise be needed.

\section{Other Recent Proposals}

Both chambers of Congress are also working in parallel on high drug price proposals. Speaker of the House Nancy Pelosi released her version in September 2019, the "Lower Drug Costs Now Act of 2019" (H.R. 3). ${ }^{4}$ This bill would not only permit the HHS to negotiate drug prices, it would set a maximum price cap for a minimum of 25 and maximum of 250 per year of the most expensive brand name drugs with limited competition. The price cap will be based on foreign country prices (120\% of the average of Australia, Canada, France, Germany, Japan, and the United Kingdom). It also has a provision to limit price increases once a drug is on the market through and inflationary rebate. While this bill doesn't address any of the concerns with the Administration's IPI model, and in many ways goes even further to penalize innovation, there are laudable components. Most importantly, the bill would help with patient out-of-pocket costs by capping the amount of Medicare Part D patient expenses at \$2000. On the Senate side, the Senate Finance Committee approved the Grassley-Wyden bill "Prescription Drug Pricing Reduction Act of 2019," which also addresses out-of-pocket expenses for Medicare beneficiaries and penalizes drug manufacturers that raise prices faster than inflation. ${ }^{5}$ Notable is that this bill refrains from government price setting tied to international prices.

\section{The Problem With These Proposals}

Fundamental principles that should be part of any comprehensive package to address the problems of high drug prices should include improved access for patients, including protections against high out-of-pocket costs for needed therapies without reducing or limiting strong incentives for innovation and R\&D in high-risk clinical areas. In addition, polices that provide strong incentives for "high-value" innovation and support for continued real-world evidence collection to better measure quality and value outcomes will be critical. While some of the proposals have included provisions that limit patient out-ofpocket costs, none have addressed drug prices in a way that will incentivize high-value innovation that considers the value that the therapy brings to patients, the health care system, or society.

One approach that could begin to bring in the value that the therapy brings and patient priorities into the equation is known as "evidence-based" or "value-based" pricing. More transparent and methodologically justified prices that are tied to the benefits and value a product brings to a patient population might offer a more reasonable approach. For example, the Institute for Clinical and Economic Research (ICER) develops models that aim to help payers better understand what valuebased prices might be for a given technology and anticipated use. While not broadly embraced (and also heavily criticized), health economic analyses or value assessment approaches like these more generally could - depending on implementationbecome an important first step toward tightly tying the price of the drug to the potential value it brings. Criticisms of these approaches include lack of generally accepted approaches for truly reflecting the patient's perspective, not yet being inclusive enough of patient priorities, and that models tend to be heavily influenced by assumptions about the use of the product, patient populations, and the potential impact the drug will have on meaningful outcome measures. Further, while using methods based on randomized clinical trial data or real-world evidence to set a price late in clinical development could possibly challenge early investment decisions to pursue product development based on an assumed price. That said, instead of adopting a single method or model, embracing general principles for the uses of value assessment techniques, approaches for 
including patient priorities, approaches for conducting sensitivity analyses, and approaches for updating models with realworld evidence by the pharmaceutical industry, could facilitate the drug pricing debate in a much more productive way that could ultimately serve patients and access to the therapies they need in a better way. Beyond more transparent value- or evidence-based pricing, actually tying the payments for drugs to the actual observed outcomes in the patient populations, or value-based payment (VBP) approaches can also help improve access for patients. VBP approaches can help address issues such as remaining payer uncertainty regarding how well a specific drug works in their actual covered population and help ensure that the payments provide good "value for money". Also highlighted by the Trump Blueprint for drug prices, a recent whitepaper by the Duke-Margolis Center for Health Policy addressed this issue in a proposed set of VBP arrangements for transformative gene therapies. ${ }^{6}$

Proposals from the House and the Administration target the most innovative (and expensive) therapies in the pipeline by setting prices, not based on the benefits these therapies bring to patients, but simply based on how much foreign governments are paying. This will have an impact on future development of treatment that address significant unmet needs for patients. The pharmaceutical industry and stakeholders across the health care system should more proactively consider a broad set of approaches that bring more transparency and rigor to how prices payments reflect patient priorities and value.

\section{Gregory W. Daniel, PhD, MPH, RPh Editor-in-Chief}

\section{Author's Note}

The opinions expressed in this article are those of the author and should not be interpreted as the position of his employer.

\section{Declaration of Conflicting Interests}

No potential conflicts were declared.

\section{Funding}

No financial support of the research, authorship, and/or publication of this article was declared.

\section{References}

1. Centers for Medicare \& Medicaid Services. ANPRM international pricing index model Medicare part B drugs. https:// www.cms.gov/newsroom/fact-sheets/anprm-international-pric ing-index-model-medicare-part-b-drugs. Accessed September 20, 2019.

2. Schulthess, Gassull, and Maisel. Tying Medicare Part B drug prices to international reference pricing will devastate R\&D. Therapeutic Innovation \& Regulatory Science. 2019:53(6).

3. CMS's International Pricing Model for Medicare Part B drugs: implementation issues. Health Affairs Blog, July 9, 2019. DOI: 10.1377/hblog20190708.294165.

4. https://waysandmeans.house.gov/sites/democrats.waysand means.house.gov/files/documents/Lower\%20Drug\%20Costs $\% 20$ Now\%20Act.pdf

5. Grassley, Wyden introduce major prescription drug pricing reform to lower costs for Americans. US Senate Committee on Finance. https:/www.finance.senate.gov/chairmans-news/ grassley-wyden-introduce-major-prescription-drug-pricingreform-to-lower-costs-for-americans. Published July 23, 2019.

6. Breakthroughs and barriers: advancing value-based payment for transformative therapies, May 2019. Duke-Margolis Center for Health Policy. https://healthpolicy.duke.edu/sites/default/ files/u31/advancing_vbp_for_transformative_therapies.pdf 